\title{
A drift correction procedure for ICP-AES systems
}

\author{
Ana Marcos and Steve J. Hill \\ Department of Environmental Sciences, Plymouth Environmental Research Center, University \\ of Plymouth, Drake Circus, Plymouth, UK PLA 8AA
}

\section{Received 25th February 2000, Accepted 5th April 2000 Published on the Web 30th May 2000}

A method is reported for correction of long-term drift in ICP-AES measurements. The change in the intensity of thirty emission lines was monitored over eight hours without recalibration of the instrument. Drift values were found to give errors of up to $20 \%$ with respect to the first measurement. The suggested procedure utilises the drift pattern of an intrinsic plasma line, Ar $404.597 \mathrm{~nm}$, and the results of a principal component analysis to remove the drift error. After correction, the drift values drop to less than $\pm 2 \%$.

\section{Introduction}

Inductively coupled plasma atomic emission spectrometry (ICP-AES) is a well established technique for routine analysis. ${ }^{1}$ Multi-element determinations, high selectivity and limits of detection below the $\mu \mathrm{g} \mathrm{g}^{-1}$ level have led to a wide range of applications in areas such as food science, environmental and clinical analysis.

However, in routine use, long-term drift may be a disadvantage of the ICP-AES technique, and in practice requires the analyst to either regularly recalibrate the instrument or match samples with one or several internal standards to be able to correct some of the drift error. Both options are time consuming. The correcting method suggested here avoids recalibration and or sample matching with an internal standard element, by use of an intrinsic plasma line.

Previous work ${ }^{2,3}$ on ICP-AES systems has shown the convenience of working at robust conditions, low nebuliser gas flow rate and high rf power. At these conditions, signals are more stable and their drift patterns are highly correlated between all the analyte lines and so, internal standardisation methods may correct for long-term drift error. Unfortunately,

Table 2 ICP-AES operating conditions

\begin{tabular}{ll}
\hline Rf power & $1000 \mathrm{~W}$ \\
Injector diameter & $2 \mathrm{~mm}$ \\
Nebuliser type & Cross flow pneumatic nebuliser \\
Nebuliser flow & $0.9 \mathrm{~L} \mathrm{~min}^{-1}$ \\
Plasma flow & $15 \mathrm{~L} \mathrm{~min}^{-1}$ \\
Auxiliary flow & $0.8 \mathrm{~L} \mathrm{~min}^{-1}$ \\
Sample uptake rate & $1.0 \mathrm{~L} \mathrm{~min}-1$ \\
Viewing height & $12 \mathrm{~mm}^{-1}$ \\
Read time & $10-20 \mathrm{~s}$ \\
\hline
\end{tabular}

Table 1 Emission lines used in study

\begin{tabular}{|c|c|c|c|c|c|}
\hline Element & $\lambda / \mathrm{nm}$ & Intensity, $I_{\mathrm{n}} / I_{\mathrm{b}}{ }^{a}$ & $\mathrm{EE}=\lambda^{b} / \mathrm{eV}$ & $\mathrm{IP}^{c} / \mathrm{eV}$ & $\mathrm{EP}+\mathrm{IP} d / \mathrm{eV}$ \\
\hline $\mathrm{Al}(\mathrm{I})$ & 396.152 & 10.5 & 3.13 & - & 3.1 \\
\hline $\mathrm{Ba}$ (II) & 230.424 & 73.0 & 5.38 & 5.21 & $\geqslant 10.6$ \\
\hline $\mathrm{Ba}$ (II) & 233.527 & 75.0 & 5.31 & 5.21 & 11.2 \\
\hline $\mathrm{Ca}(\mathrm{I})$ & 422.673 & 1.5 & 2.99 & - & 2.9 \\
\hline $\mathrm{Ca}$ (II) & 317.933 & 1.5 & 3.90 & 6.11 & 13.1 \\
\hline $\mathrm{Cd}(\mathrm{I})$ & 228.802 & 110 & 5.42 & - & 5.4 \\
\hline $\mathrm{Cd}$ (II) & 226.502 & 120 & 5.47 & 8.99 & 14.4 \\
\hline Co (I) & 340.512 & No data & 3.64 & - & 14.0 \\
\hline Co (II) & 228.616 & 43.0 & 5.42 & 7.88 & 14.3 \\
\hline $\mathrm{Cr}(\mathrm{I})$ & 357.869 & 13.0 & 3.46 & - & $\geqslant 3.46$ \\
\hline $\mathrm{Cr}$ (II) & 267.716 & 42.0 & 4.63 & 6.77 & $\geqslant 11.4$ \\
\hline $\mathrm{Cu}(\mathrm{I})$ & 324.754 & 56.0 & 3.82 & - & 3.8 \\
\hline $\mathrm{Cu}$ (II) & 224.700 & 39.0 & 5.52 & 7.73 & 15.9 \\
\hline $\mathrm{Fe}(\mathrm{II})$ & 259.940 & 48.0 & 4.77 & 7.90 & $\geqslant 12.7$ \\
\hline $\operatorname{Mg}(\mathrm{I})$ & 285.213 & No data & 4.35 & - & 4.3 \\
\hline $\mathrm{Mg}$ (II) & 279.079 & 1.0 & 4.44 & 7.65 & $\geqslant 12.1$ \\
\hline Mn (I) & 403.076 & 6.8 & 3.08 & - & 3.1 \\
\hline Mn (II) & 257.610 & 220 & 4.81 & 7.43 & 12.2 \\
\hline $\mathrm{Na}(\mathrm{I})$ & 589.592 & 43.0 & 2.10 & - & 2.1 \\
\hline $\mathrm{Ni}(\mathrm{I})$ & 232.003 & 20.0 & 5.34 & - & $\geqslant 5.34$ \\
\hline $\mathrm{Ni}$ (II) & 231.604 & 15.0 & 5.35 & 7.64 & $\geqslant 13.0$ \\
\hline $\mathrm{Pb}$ (II) & 220.353 & 70.0 & 5.62 & 7.42 & 14.7 \\
\hline Ti (II) & 379.280 & No data & 3.27 & 6.83 & $\geqslant 10.1$ \\
\hline $\mathrm{Zn}(\mathrm{I})$ & 213.856 & 170 & 5.80 & - & 5.8 \\
\hline Zn (II) & 202.548 & 75.0 & 6.12 & 9.39 & 15.5 \\
\hline $\operatorname{Ar}(\mathrm{I})$ & 357.229 & 2.3 & 3.47 & - & $\geqslant 3.47$ \\
\hline $\operatorname{Ar}(\mathrm{I})$ & 404.597 & 2.5 & 3.06 & - & $\geqslant 3.06$ \\
\hline $\operatorname{Ar}(\mathrm{I})$ & 420.068 & 50 & 2.95 & - & $\geqslant 2.95$ \\
\hline $\operatorname{Ar}(\mathrm{I})$ & 451.074 & 21 & 2.75 & - & $\geqslant 2.75$ \\
\hline
\end{tabular}

${ }^{a}$ Ratio of net analyte intensity to background intensity (Handbook of ICP-AES, CRC Press, 1981). ${ }^{b}$ Transition emitted energy (calculated by converting $\mathrm{nm}^{-1}$ to eV). ${ }^{c}$ First ionisation potential (Handbook of Physics and Chemistry, CRC Press, 77th Edition, 1997). ${ }^{d}$ Excitation potential (P. W. Robinson, Handbook of Spectroscopy Vol.1, CRC Press, 1974). 
many ICP-AES users employ soft conditions to perform their analyses, ${ }^{4-8}$ i.e., the so called 'default conditions' which imply low rf power $(\sim 1000 \mathrm{~W})$ and a medium nebuliser flow rate $\left(\sim 1.0 \mathrm{Lmin}^{-1}\right)$. These values facilitate the use of both soft and hard emission lines and are thus more versatile. In addition, 'standard conditions' are often promoted by manufacturers. ${ }^{9}$ However, when using such working parameters, the ICP-AES technique can give very unstable signals over time and complex drift patterns. For this reason, an attempt has been made to monitor and correct the instability when using the more routine soft conditions.

The approach reported here requires the analyst only to monitor the drift of one argon line. A polynomial regression trendline is then fitted to the argon drift, and the long-term drift on the other lines is estimated using the trendline of the argon emission once modified by a correction factor, $f_{\mathrm{i}}$, which is specific for each emission line. To date, this correction factor has been estimated by employing the results of a principal component analysis performed on the data set. However, the ideal case will be to estimate $f_{\mathrm{i}}$ by using only physical properties of the emission lines.

\section{Methodology}

\section{Experimental}

A multi-element solution containing 15 analytes was repeatedly analysed over a period of $8 \mathrm{~h}$ without recalibration (100 replicates). In order to ensure stable starting conditions, $2 \mathrm{~h}$ were allowed for the instrument to 'warm up'. The change in the intensities from 30 emission lines was then followed over the time. Table 1 details the lines monitored in this study. In most cases, one atomic and one ionic line were used, in addition to four argon emission lines.

\section{Instrumentation}

The instrument employed was an OPTIMA 3000 (Perkin Elmer Corporation, Norwalk, CT, USA). This ICP-AES combines an echelle polychromator with a solid state detector, which allows simultaneous acquisition. The plasma was viewed radially. The operating conditions are described in Table 2.

Table 3 Polynomial regressions of the emission lines studied

\begin{tabular}{|c|c|c|c|c|c|c|c|c|}
\hline \multirow{2}{*}{$\begin{array}{l}\text { Emission } \\
\text { lines }\end{array}$} & \multicolumn{6}{|c|}{ Polynomial parameters } & \multicolumn{2}{|c|}{ Statistics } \\
\hline & $\beta_{0}$ & $\beta_{1}$ & $\beta_{2}$ & $\beta_{3}$ & $\beta_{4}$ & $\beta_{5}$ & $s$ & $r$ \\
\hline $\mathrm{Al}(\mathrm{I})$ & 0.107 & 0.313 & -0.014 & $3.5 \mathrm{E}-04$ & $-3.7 \mathrm{E}-06$ & $1.4 \mathrm{E}-08$ & 0.23 & 0.992 \\
\hline $\mathrm{Ca}(\mathrm{I})$ & 0.033 & 0.071 & -0.0038 & $1.1 \mathrm{E}-04$ & $-1.3 \mathrm{E}-06$ & $5.5 \mathrm{E}-09$ & 0.13 & 0.886 \\
\hline $\mathrm{Cd}(\mathrm{I})$ & -0.048 & 0.316 & -0.0133 & $3.2 \mathrm{E}-04$ & $-3.4 \mathrm{E}-06$ & $1.2 \mathrm{E}-08$ & 0.31 & 0.989 \\
\hline Co (I) & -0.074 & 0.196 & -0.0095 & 0.00026 & $-3.0 \mathrm{E}-06$ & $1.2 \mathrm{E}-08$ & 0.25 & 0.981 \\
\hline $\mathrm{Cr}(\mathrm{I})$ & 0.016 & 0.045 & -0.0027 & 8.9E-05 & $-1.2 \mathrm{E}-06$ & $5.4 \mathrm{E}-09$ & 0.13 & 0.865 \\
\hline $\mathrm{Cu}(\mathrm{I})$ & 0.011 & 0.124 & -0.0062 & $1.7 \mathrm{E}-04$ & $-2.0 \mathrm{E}-06$ & $8.2 \mathrm{E}-09$ & 0.16 & 0.973 \\
\hline $\mathrm{Mg}(\mathrm{I})$ & 0.047 & 0.257 & -0.0116 & $2.9 \mathrm{E}-04$ & $-3.1 \mathrm{E}-06$ & $1.1 \mathrm{E}-08$ & 0.20 & 0.990 \\
\hline Mn (I) & -0.026 & 0.047 & -0.0029 & $9.2 \mathrm{E}-05$ & $-1.2 \mathrm{E}-06$ & $5.4 \mathrm{E}-09$ & 0.13 & 0.859 \\
\hline $\mathrm{Na}(\mathrm{I})$ & 0.070 & 0.039 & -0.0026 & $6.8 \mathrm{E}-05$ & $-8.4 \mathrm{E}-07$ & 3.7E-09 & 0.14 & 0.958 \\
\hline $\mathrm{Ni}(\mathrm{I})$ & 0.047 & 0.319 & -0.0145 & 3.6E-04 & $-3.8 \mathrm{E}-06$ & $1.4 \mathrm{E}-08$ & 0.30 & 0.986 \\
\hline $\mathrm{Zn}(\mathrm{I})$ & 0.254 & 0.462 & -0.02 & 4.7E-04 & $-4.8 \mathrm{E}-06$ & $1.7 \mathrm{E}-08$ & 0.35 & 0.992 \\
\hline $\mathrm{Ba}$ (II) & -0.012 & 0.885 & -0.0382 & 9.0 E-04 & $-9.0 \mathrm{E}-06$ & $3.1 \mathrm{E}-08$ & 0.66 & 0.993 \\
\hline $\mathrm{Ba}$ (II) & 0.321 & 0.832 & -0.0348 & 8.1E-04 & $-8.1 \mathrm{E}-06$ & $2.8 \mathrm{E}-08$ & 0.58 & 0.994 \\
\hline $\mathrm{Ca}$ (II) & 0.075 & 0.447 & -0.0194 & 4.7E-04 & $-4.9 \mathrm{E}-06$ & $1.8 \mathrm{E}-08$ & 0.31 & 0.994 \\
\hline $\mathrm{Cd}$ (II) & 0.122 & 0.238 & -0.0108 & 2.7E-04 & $-2.9 \mathrm{E}-06$ & $1.1 \mathrm{E}-08$ & 0.22 & 0.988 \\
\hline Co (II) & -0.003 & 0.404 & -0.0171 & 4.1E-04 & $-4.3 \mathrm{E}-06$ & $1.6 \mathrm{E}-08$ & 0.44 & 0.985 \\
\hline $\mathrm{Cr}$ (II) & -0.068 & 0.606 & -0.0267 & $6.4 \mathrm{E}-04$ & $-6.5 \mathrm{E}-06$ & 2.3E-08 & 0.41 & 0.994 \\
\hline $\mathrm{Cu}$ (II) & 0.053 & 0.381 & -0.0169 & 4.1E-04 & $-4.4 \mathrm{E}-06$ & $1.6 \mathrm{E}-08$ & 0.25 & 0.993 \\
\hline $\mathrm{Fe}$ (II) & 0.271 & 0.423 & -0.0188 & 4.6E-04 & $-4.8 \mathrm{E}-06$ & $1.8 \mathrm{E}-08$ & 0.29 & 0.993 \\
\hline $\mathrm{Mg}$ (II) & -0.204 & 0.233 & -0.01 & $2.5 \mathrm{E}-04$ & $-2.8 \mathrm{E}-06$ & $1.1 \mathrm{E}-08$ & 0.23 & 0.988 \\
\hline Mn (II) & 0.334 & 0.540 & -0.0234 & $5.5 \mathrm{E}-04$ & $-5.7 \mathrm{E}-06$ & $2.0 \mathrm{E}-08$ & 0.36 & 0.994 \\
\hline $\mathrm{Ni}$ (II) & -0.206 & 0.282 & -0.0126 & $3.1 \mathrm{E}-04$ & $-3.3 \mathrm{E}-06$ & $1.2 \mathrm{E}-08$ & 0.28 & 0.984 \\
\hline $\mathrm{Pb}$ (II) & 0.534 & 0.016 & -0.0016 & $5.8 \mathrm{E}-05$ & $-7.6 \mathrm{E}-07$ & $3.2 \mathrm{E}-09$ & 0.43 & 0.442 \\
\hline Ti (II) & 0.193 & 0.353 & -0.0154 & 3.7E-04 & $-3.9 \mathrm{E}-06$ & $1.4 \mathrm{E}-08$ & 0.23 & 0.994 \\
\hline $\mathrm{Zn}$ (II) & 1.031 & 0.503 & -0.0215 & $5.2 \mathrm{E}-04$ & $-5.5 \mathrm{E}-06$ & $2.0 \mathrm{E}-08$ & 0.53 & 0.988 \\
\hline${ }^{357} \mathrm{Ar}$ & 0.048 & 0.617 & -0.0239 & $5.1 \mathrm{E}-04$ & $-4.6 \mathrm{E}-06$ & $1.4 \mathrm{E}-08$ & 0.56 & 0.993 \\
\hline${ }^{404} \mathrm{Ar}$ & -0.011 & 0.415 & -0.0187 & 4.4E-04 & $-4.4 \mathrm{E}-06$ & $1.6 \mathrm{E}-08$ & 0.32 & 0.991 \\
\hline${ }^{420} \mathrm{Ar}$ & 0.033 & 0.593 & -0.0249 & $5.5 \mathrm{E}-04$ & $-5.2 \mathrm{E}-06$ & $1.7 \mathrm{E}-08$ & 0.34 & 0.996 \\
\hline${ }^{451} \mathrm{Ar}$ & 0.004 & 0.588 & -0.0242 & 5.3E-04 & $-4.9 \mathrm{E}-06$ & $1.6 \mathrm{E}-08$ & 0.36 & 0.996 \\
\hline
\end{tabular}
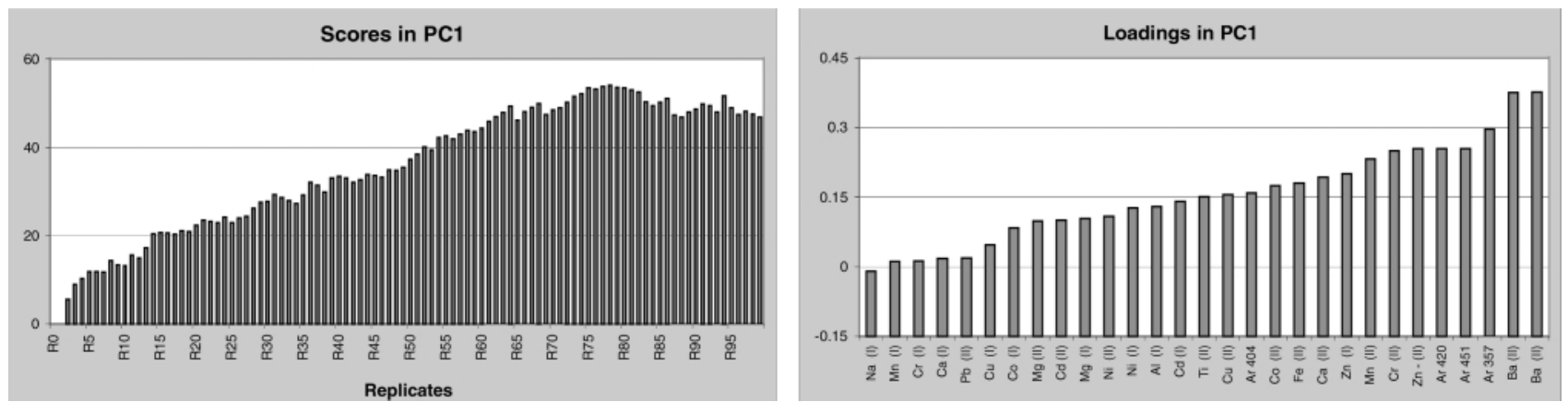

Fig. 1 Details of the principal component analysis performed to the data. Data employed, drift values; samples, the 100 replicates; variables, the 30 emission lines monitored; pretreatment, none; results, PC1 accounts for $\sim 100 \%$ of the variation. 


\section{The correction procedure}

The different steps employed in the correction procedure are described below:

1. The trendline of one of the argon lines $(404.597 \mathrm{~nm}) \dagger$ is calculated by employing a polynomial model up to the 5th order:

† This argon line was chosen because of all the argon lines monitored, the drift pattern most closely resembled that of the analyte lines.

$$
y=\beta_{0}+\beta_{1} n+\beta_{2} n^{2}+\beta_{3} n^{3}+\beta_{4} n^{4}+\beta_{5} n^{5}
$$

Where $y$ refers to the measured drift error and $n$ refers to the replicate number.

2. A correction factor, $f_{\mathrm{i}}$, specific for each emission line is determined using the results of a principal component analysis, PCA, performed on the data:

$$
f_{\mathrm{i}}=\frac{L_{\mathrm{Anal}_{\mathrm{i}}}}{L_{\mathrm{Ar} 404}}
$$

\begin{tabular}{|c|c|c|c|c|c|c|c|c|}
\hline \multirow{3}{*}{$\begin{array}{l}\text { Emission } \\
\text { lines }\end{array}$} & \multirow{2}{*}{\multicolumn{6}{|c|}{ Ratio $^{a}$}} & \multicolumn{2}{|l|}{ From the PCA } \\
\hline & & & & & & & \multirow{2}{*}{$\begin{array}{l}\text { Loadings ratio } \\
\text { Ratio (analyte/Ar) }\end{array}$} & \multirow{2}{*}{$\begin{array}{l}\text { Loadings } \\
\text { in } \mathrm{PC} 1\end{array}$} \\
\hline & $\beta_{0}$ & $\beta_{1}$ & $\beta_{2}$ & $\beta_{3}$ & $\beta_{4}$ & $\beta_{5}$ & & \\
\hline $\mathrm{Al}(\mathrm{I})$ & -9.47 & 0.76 & 0.75 & 0.79 & 0.84 & 0.89 & 0.82 & 0.13 \\
\hline $\mathrm{Ca}(\mathrm{I})$ & -2.91 & 0.17 & 0.20 & 0.24 & 0.29 & 0.35 & 0.11 & 0.02 \\
\hline $\mathrm{Cd}(\mathrm{I})$ & 4.25 & 0.76 & 0.71 & 0.74 & 0.77 & 0.79 & 0.89 & 0.14 \\
\hline Co (I) & 6.51 & 0.47 & 0.50 & 0.59 & 0.68 & 0.76 & 0.53 & 0.08 \\
\hline $\mathrm{Cr}(\mathrm{I})$ & -1.40 & 0.11 & 0.15 & 0.20 & 0.27 & 0.35 & 0.08 & 0.01 \\
\hline $\mathrm{Cu}(\mathrm{I})$ & -0.97 & 0.30 & 0.33 & 0.39 & 0.46 & 0.52 & 0.30 & 0.05 \\
\hline $\operatorname{Mg}(\mathrm{I})$ & -4.13 & 0.62 & 0.62 & 0.65 & 0.69 & 0.73 & 0.65 & 0.10 \\
\hline Mn (I) & 2.34 & 0.11 & 0.15 & 0.21 & 0.27 & 0.34 & 0.07 & 0.01 \\
\hline $\mathrm{Na}(\mathrm{I})$ & -6.19 & 0.09 & 0.14 & 0.15 & 0.19 & 0.24 & -0.06 & -0.01 \\
\hline $\mathrm{Ni}(\mathrm{I})$ & -4.13 & 0.77 & 0.77 & 0.82 & 0.87 & 0.92 & 0.80 & 0.12 \\
\hline Zn (I) & -22.48 & 1.11 & 1.07 & 1.08 & 1.10 & 1.10 & 1.26 & 0.19 \\
\hline $\mathrm{Ba}$ (II) & 1.05 & 2.13 & 2.04 & 2.04 & 2.03 & 2.01 & 2.37 & 0.37 \\
\hline $\mathrm{Ba}(\mathrm{II})$ & -28.44 & 2.01 & 1.86 & 1.84 & 1.83 & 1.81 & 2.38 & 0.37 \\
\hline $\mathrm{Ca}$ (II) & -6.64 & 1.08 & 1.03 & 1.06 & 1.10 & 1.13 & 1.21 & 0.19 \\
\hline $\mathrm{Cd}$ (II) & -10.84 & 0.57 & 0.58 & 0.62 & 0.66 & 0.71 & 0.63 & 0.10 \\
\hline Co (II) & 0.31 & 0.97 & 0.91 & 0.93 & 0.96 & 0.99 & 1.10 & 0.17 \\
\hline $\mathrm{Cr}$ (II) & 6.05 & 1.46 & 1.43 & 1.45 & 1.47 & 1.47 & 1.57 & 0.24 \\
\hline $\mathrm{Cu}$ (II) & -4.71 & 0.92 & 0.90 & 0.94 & 1.00 & 1.05 & 0.98 & 0.15 \\
\hline $\mathrm{Fe}$ (II) & -23.95 & 1.02 & 1.00 & 1.05 & 1.10 & 1.14 & 1.13 & 0.18 \\
\hline $\mathrm{Mg}$ (II) & 18.09 & 0.56 & 0.53 & 0.58 & 0.64 & 0.70 & 0.62 & 0.10 \\
\hline Mn (II) & -29.53 & 1.30 & 1.25 & 1.26 & 1.28 & 1.29 & 1.46 & 0.23 \\
\hline $\mathrm{Ni}$ (II) & 18.24 & 0.68 & 0.67 & 0.70 & 0.74 & 0.77 & 0.68 & 0.11 \\
\hline $\mathrm{Pb}$ (II) & -47.21 & 0.04 & 0.08 & 0.13 & 0.17 & 0.20 & 0.12 & 0.02 \\
\hline $\mathrm{Ti}$ (II) & -17.11 & 0.85 & 0.82 & 0.85 & 0.88 & 0.91 & 0.95 & 0.15 \\
\hline $\mathrm{Zn}$ (II) & -91.23 & 1.21 & 1.14 & 1.19 & 1.24 & 1.27 & 1.60 & 0.25 \\
\hline${ }^{357} \mathrm{Ar}$ & -4.22 & 1.49 & 1.27 & 1.16 & 1.03 & 0.89 & 1.87 & 0.29 \\
\hline${ }^{404} \mathrm{Ar}$ & 1.00 & 1.00 & 1.00 & 1.00 & 1.00 & 1.00 & 1.00 & 0.15 \\
\hline${ }^{420} \mathrm{Ar}$ & -2.91 & 1.43 & 1.33 & 1.25 & 1.17 & 1.09 & 1.60 & 0.25 \\
\hline${ }^{451} \mathrm{Ar}$ & -0.32 & 1.42 & 1.29 & 1.20 & 1.10 & 1.00 & 1.60 & 0.25 \\
\hline
\end{tabular}

Table 4 Comparison of the polynomial parameters. Where to apply the specific correction factor?

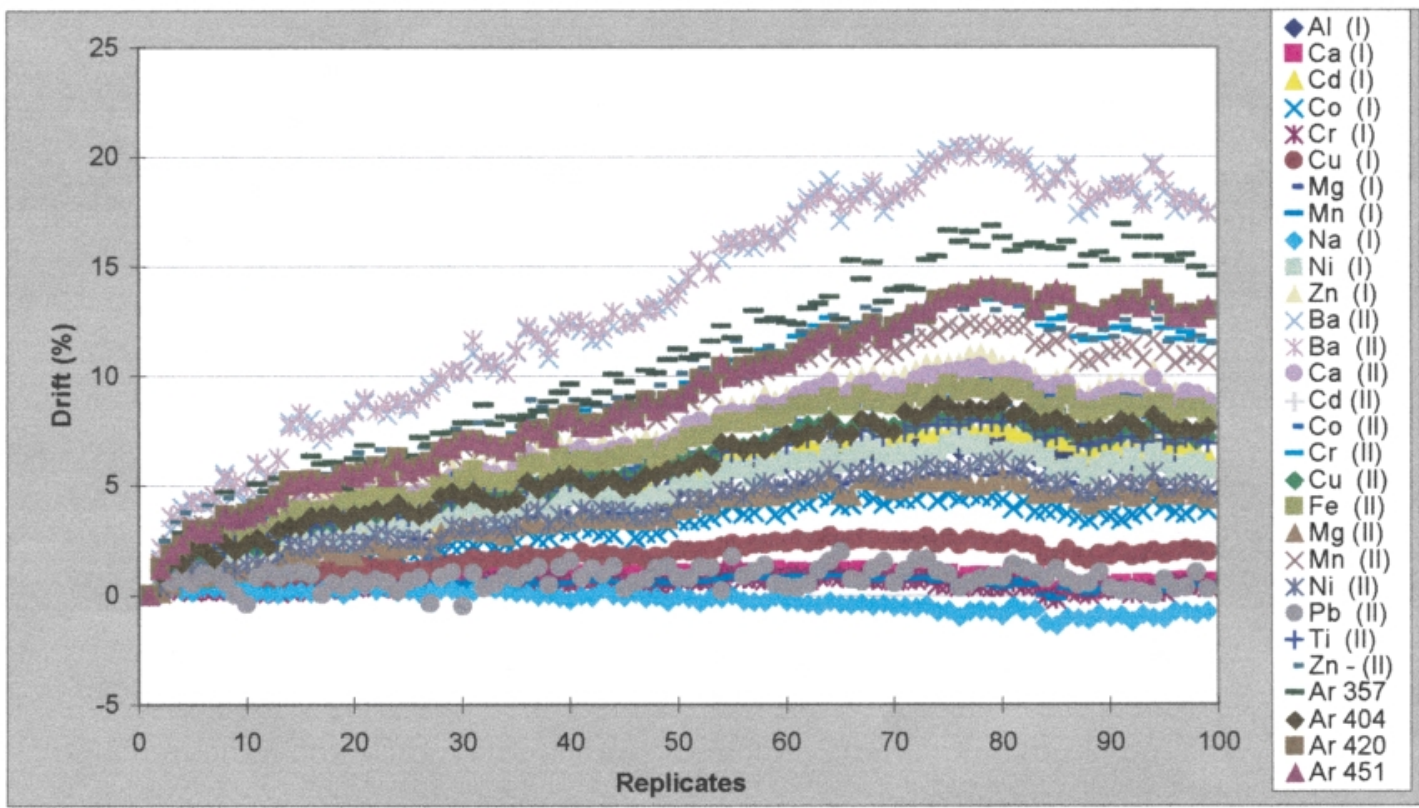

Fig. 2 Drift patterns over $8 \mathrm{~h}$ of analysis. 
Where $L_{\mathrm{Anal}_{\mathrm{i}}}$ refers to the loading of analyte line i on PC1, and $L_{\mathrm{Ar}_{404}}$ refers to the loading of argon line $404.597 \mathrm{~nm}$ on PC1.

3 . The drift on each emission line is then estimated using the trendline of the argon, and the correction factor specific for the line, $f_{\mathrm{i}}$. All the parameters, $\beta$, of the argon trendline in $n$, (i.e., $\beta_{1}$, $\beta_{2}, \beta_{3}, \beta_{4}, \beta_{5}$, not $\beta_{0}$ ) are multiplied by $f_{\mathrm{i}}$ :

$$
\begin{aligned}
y_{\mathrm{Anal}_{\mathrm{i}}=}= & \beta_{0}^{\mathrm{Ar}_{404}}+f_{\mathrm{i}} \beta_{1}^{\mathrm{Ar}_{404}} n+f_{\mathrm{i}} \beta_{2}^{\mathrm{Ar}_{404}} n^{2}+f_{\mathrm{i}} \beta_{3}^{\mathrm{Ar}_{404} n^{3}} \\
& +f_{\mathrm{i}} \beta_{4}^{\mathrm{Ar}_{404}} n^{4}+f_{\mathrm{i}} \beta_{5}^{\mathrm{Ar}_{404}} n^{5}
\end{aligned}
$$

4. The estimated drift is removed from the measured data to create the 'corrected data set'.

5. The long-term drift on the corrected data set is calculated and compared to the drift of the data before correction.

Calculation of the trendlines. Any curve can be fitted using a polynomial regression to the $n$th order. Increasing the order has the effect of improving the fit, i.e., the regression coefficient, $r$, will tend to one. In this study, the drift patterns have been regressed to polynomial curves up to the 5th order, which gives an improved regression coefficient but with a practical number of parameters: six [eqn. (1)]. The polynomial equations were calculated using the software 'CurveExpert, version 1.3' (Daniel Hyams \& Microsoft Corporation, Redmond, WA, USA).

Although, only the trendline of argon $404.597 \mathrm{~nm}$ is used in the correction procedure, the polynomial regressions of all the other lines studied were also calculated. This facilitated a comparison of the polynomial parameters of every line to those of the argon trendline, and thus allowed us to determine where, the specific correction factor should be applied. The parameters found are reported in Table 3.

The correction factor. The specific correction factors have been calculated by employing the loadings of a principal component analysis (Fig. 1) performed on the data set. The loading in the first principal component of every emission line is compared to the loading of the argon line [eqn. (2)]. The 'loading ratios' have been employed as specific correction factors.

In order to investigate where to apply the specific correction factor, the polynomial parameters of all the fitted curves were compared. It was observed that the ratio of all parameters

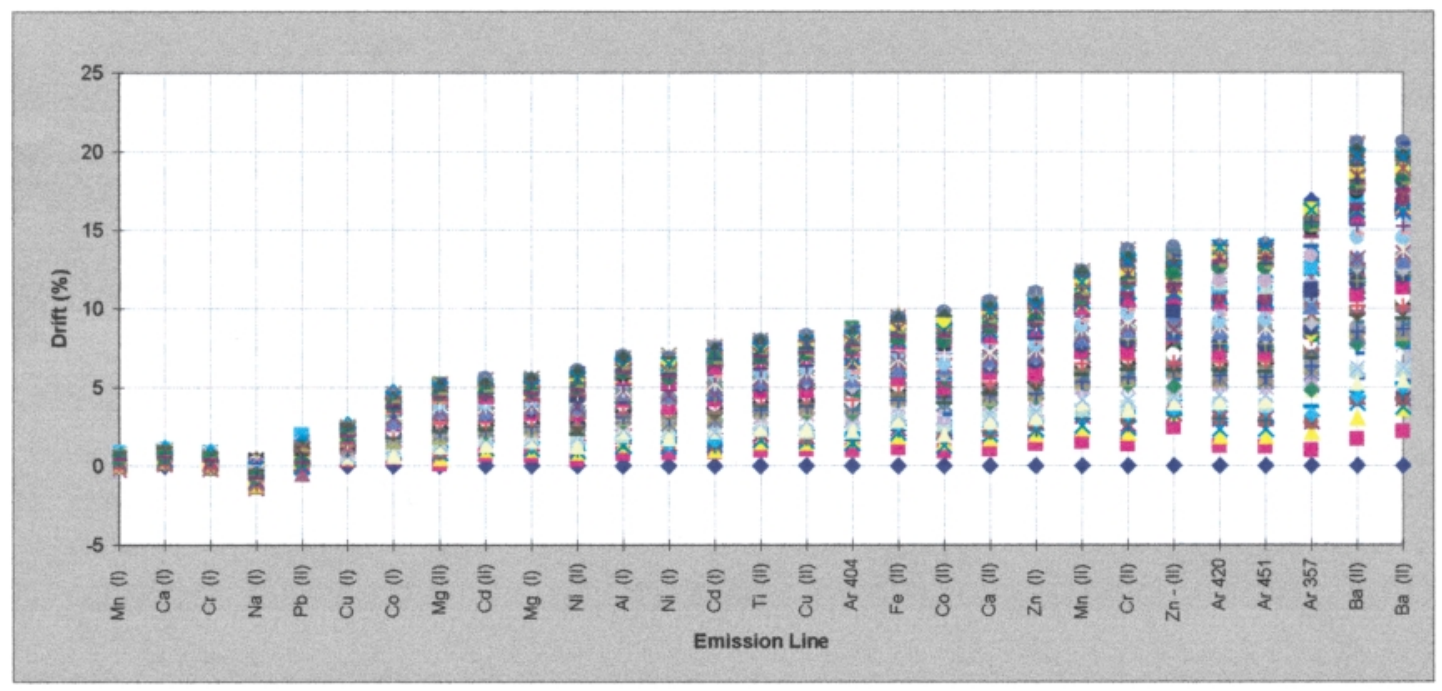

Fig. 3 Ranges of variation for each monitored emission line.

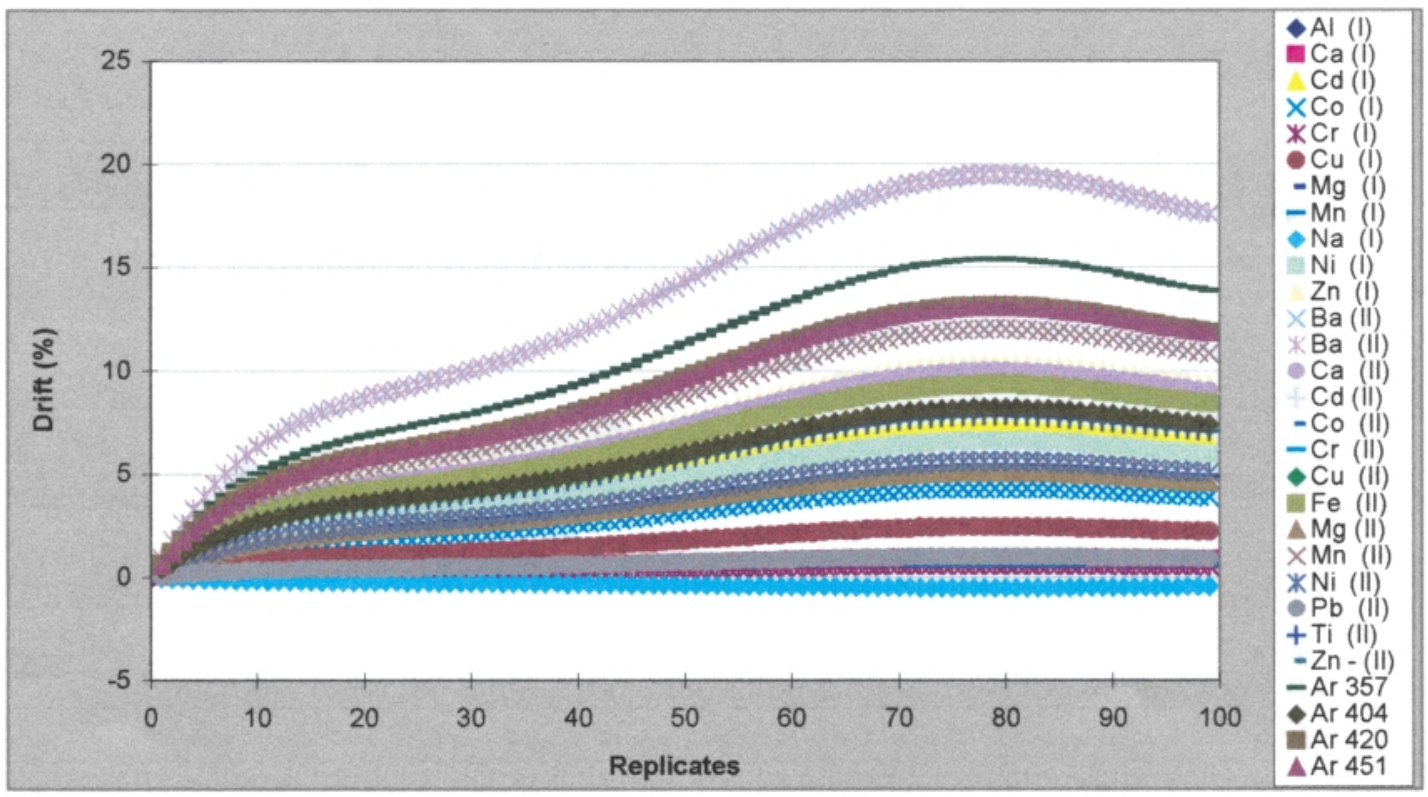

Fig. 4 Estimated drift using the suggested correction procedure. 
multiplying the replicates $n$ of the analyte line to those of the argon line were constant, and this ratio was indeed similar to the ratio of the PCA loadings (Table 4). Thus, the correction factors were calculated using the PCA loading ratios and applied to the argon trendline by multiplying every parameter, except the intercept, $\beta_{0}$. The drift on each analyte line was then estimated by eqn. (3).

\section{Results and discussion}

Fig. 1 shows the evolution of the drift on the 30 emission lines monitored during $8 \mathrm{~h}$ of repeated determinations. It can be seen that the drift patterns are similar for all the lines, but with a different gradient at the beginning of the analysis.

If the range of variation of each emission line is plotted, Fig. 2, it can be seen how some lines remain very stable during the whole experiment whilst others have drift values up to $20 \%$. In general, the atomic lines are more stable than the ionic lines, a feature almost certainly due to the low rf power employed $(1000 \mathrm{~W})$, which tends to make hard lines more vulnerable to drift. Certainly, the variation in the sequence of lines is not random (Fig. 3), and so some physical characteristic of the emission lines probably accounts for these differences. A number of fundamental properties of the lines have been correlated to the variation sequence, e.g., emission energy, excitation energy and intensity of the lines, in order to estimate the correction factor. To date however, we have not found good correlation with any of the physical characteristics tested, and thus the loading ratio has been retained as the best approximation to calculate the specific correction factors.

The 'estimated drift' for each emission line monitored is shown in Fig. 4. This was calculated using the polynomial fit for the emission line of argon $404.597 \mathrm{~nm}$ and the specific correction factors. The remaining drift error after correction has been plotted in Fig. 5. It can be observed that the long-term drift drops from around $20 \%$ in the original data set, Fig. 2, to better than $2 \%$ after applying the correction procedure, Fig. 5. The factors of improvement are detailed in Table 5.

The suggested correction procedure has been shown to successfully remove most of the drift from the data when using 'typical' default instrumental conditions. The procedure employs the drift pattern of an intrinsic plasma line, the emission line of argon at $404 \mathrm{~nm}$, instead of an added internal standard, and only requires the results of a previous principal component analysis to estimate the specific correction factors.

The phenomenon which cause the sequence described above are still being investigated as are the potential effects due to the addition of a more complex chemical matrix.

Table 5 Improvement in drift obtained by employing the suggested correction procedure after $8 \mathrm{~h}$ of analysis

\begin{tabular}{|c|c|c|c|c|c|c|}
\hline \multirow[b]{2}{*}{$\begin{array}{l}\text { Emission } \\
\text { lines }\end{array}$} & \multicolumn{3}{|c|}{$\begin{array}{l}\text { Long-term drift } \\
\text { after } 8 \mathrm{~h} \text { of analysis }\end{array}$} & \multicolumn{3}{|c|}{ Maximum drift observed } \\
\hline & $\begin{array}{l}\text { Measured } \\
(\%)\end{array}$ & $\begin{array}{l}\text { After } \\
\text { correction } \\
(\%)\end{array}$ & $F_{\mathrm{I}}^{a}$ & $\begin{array}{l}\text { Measured } \\
(\%)\end{array}$ & $\begin{array}{l}\text { After } \\
\text { correction } \\
(\%)\end{array}$ & $F_{\mathrm{I}}$ \\
\hline $\mathrm{Al}(\mathrm{I})$ & 6.0 & -0.1 & 55 & 7.0 & 0.6 & 11 \\
\hline $\mathrm{Ca}(\mathrm{I})$ & 0.5 & -0.3 & 2 & 1.2 & 0.4 & 3 \\
\hline $\mathrm{Cd}(\mathrm{I})$ & 6.3 & -0.3 & 21 & 7.7 & 0.9 & 8 \\
\hline Co (I) & 3.9 & 0.0 & 98 & 4.8 & 0.6 & 8 \\
\hline $\mathrm{Cr}(\mathrm{I})$ & 0.3 & -0.2 & 1 & 1.0 & 0.5 & 2 \\
\hline $\mathrm{Cu}(\mathrm{I})$ & 1.9 & -0.2 & 8 & 2.7 & 0.4 & 6 \\
\hline $\operatorname{Mg}(\mathrm{I})$ & 4.6 & -0.3 & 17 & 5.6 & 0.6 & 10 \\
\hline $\mathrm{Mn}(\mathrm{I})$ & 0.4 & -0.1 & 3 & 0.9 & 0.4 & 2 \\
\hline $\mathrm{Na}(\mathrm{I})$ & -0.8 & -0.3 & 3 & 0.5 & 0.7 & 1 \\
\hline $\mathrm{Ni}(\mathrm{I})$ & 5.6 & -0.3 & 19 & 7.1 & 0.7 & 11 \\
\hline $\mathrm{Zn}(\mathrm{I})$ & 9.0 & -0.3 & 27 & 11.0 & 0.6 & 17 \\
\hline $\mathrm{Ba}$ (II) & 17.4 & -0.2 & 109 & 20.5 & 1.3 & 16 \\
\hline $\mathrm{Ba}$ (II) & 17.5 & -0.1 & 136 & 20.6 & 1.3 & 16 \\
\hline $\mathrm{Ca}$ (II) & 8.8 & -0.2 & 43 & 10.4 & 0.8 & 14 \\
\hline $\mathrm{Cd}$ (II) & 4.4 & -0.3 & 16 & 5.6 & 0.5 & 10 \\
\hline Co (II) & 8.2 & 0.0 & 750 & 9.8 & 1.0 & 10 \\
\hline $\mathrm{Cr}$ (II) & 11.5 & -0.1 & 84 & 13.8 & 0.9 & 16 \\
\hline $\mathrm{Cu}$ (II) & 7.2 & -0.1 & 70 & 8.3 & 0.7 & 12 \\
\hline $\mathrm{Fe}$ (II) & 8.2 & -0.2 & 42 & 9.6 & 0.8 & 12 \\
\hline $\mathrm{Mg}$ (II) & 4.4 & -0.2 & 20 & 5.4 & 0.5 & 11 \\
\hline Mn (II) & 10.6 & -0.2 & 56 & 12.4 & 0.8 & 16 \\
\hline $\mathrm{Ni}$ (II) & 4.8 & -0.3 & 18 & 6.2 & 0.6 & 10 \\
\hline $\mathrm{Pb}$ (II) & 0.2 & -0.6 & 0 & 2.0 & 1.1 & 2 \\
\hline Ti (II) & 6.9 & -0.1 & 58 & 8.1 & 0.6 & 13 \\
\hline $\mathrm{Zn}-$ (II) & 11.4 & -0.4 & 30 & 13.9 & 1.6 & 9 \\
\hline${ }^{357} \mathrm{Ar}$ & 14.5 & 0.6 & 25 & 16.9 & 1.9 & 9 \\
\hline${ }^{404} \mathrm{Ar}$ & 7.7 & 0.2 & 34 & 8.8 & 0.5 & 16 \\
\hline${ }^{420} \mathrm{Ar}$ & 12.9 & 1.0 & 13 & 13.9 & 1.5 & 10 \\
\hline${ }^{451} \mathrm{Ar}$ & 13.1 & 1.2 & 11 & 14.1 & 1.5 & 9 \\
\hline
\end{tabular}

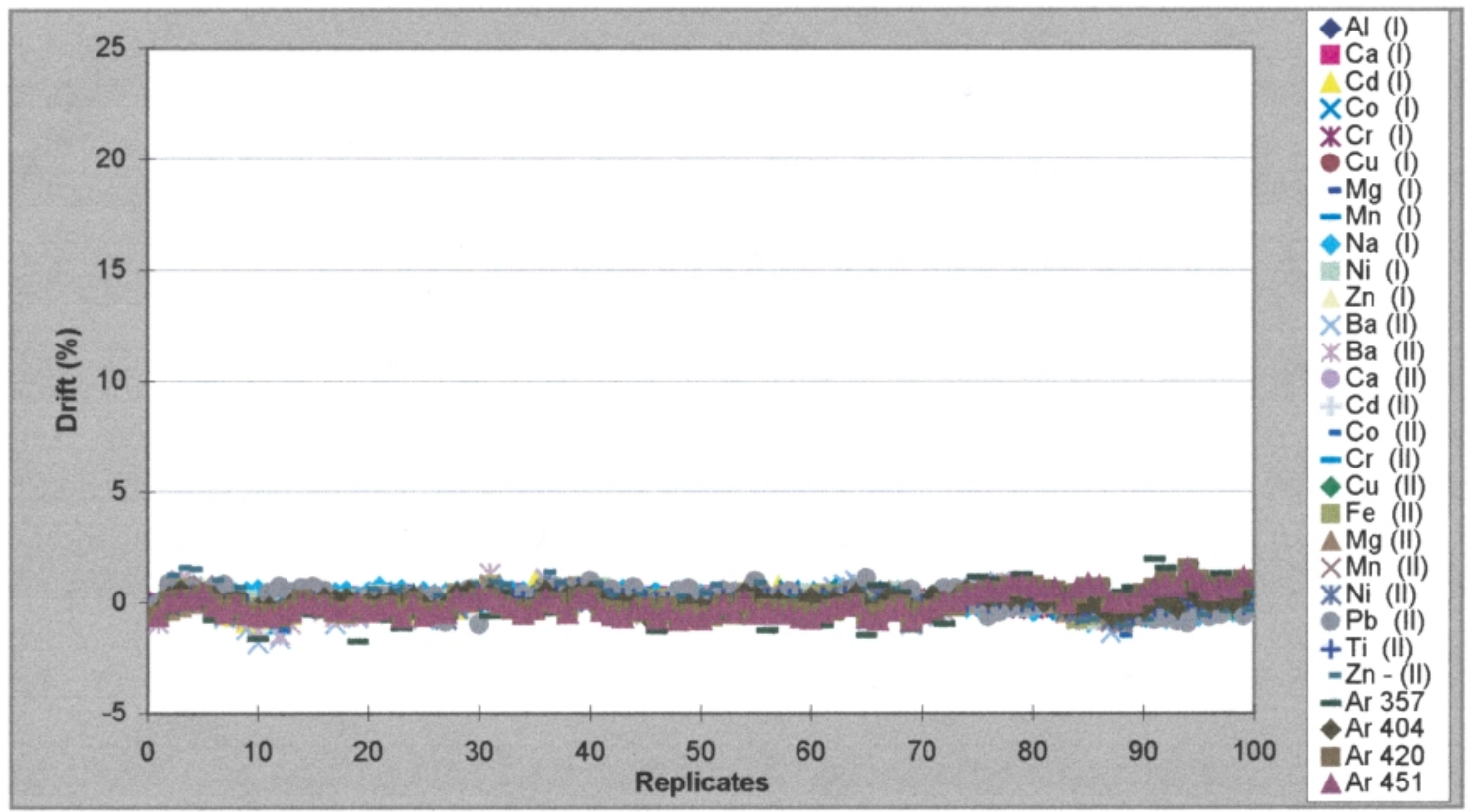

Fig. 5 Drift error remaining after correction. 


\section{Acknowledgements}

The authors wish to acknowledge Dr Mark Cave for support and inspiration, as well as the British Geological Survey (Keyworth, UK) and the University of Plymouth for financing this study.

\section{References}

1 Inductively Coupled Plasma Spectrometry and Its Applications, ed. S. J. Hill, Sheffield Academic Press, 1999.

2 X. Romero, E. Poussel and J. M. Mermet, Spectrochim. Acta, Part B, 1997, 52B, 487.
3 A. Marcos, M. Foulkes and S. J. Hill, J. Anal. At. Spectrom., submitted for publication.

4 I. Rodushkin, T. Ruth and A. Huhtasaari, Anal. Chim. Acta, 1999, 378, 191.

5 O. Abollino, M. Aceto, M. C. Bruzzoniti, E. Mentasti and C. Sarzanini, Anal. Chim. Acta, 1998, 375, 293.

6 J. A. Nobrega, Y. Gelinas, A. Krushevska and R. M. Barnes, J. Anal. At. Spectrom., 1997, 12, 1243.

7 T. Piippanen, J. Rautiainen and J. Tummavuori, Anal. Chim. Acta, 1997, 349, 327

8 E. H. VanVeen, S. Bosch and M. T. C. de Loos-Vollebregt, Spectrochim. Acta, Part B, 1997, 52, 321.

9 C. B. Boss and K. J. Fredeen, Concepts, Instrumentation and Techniques in ICP-OES, Perkin Elmer Corporation, 1997. 